\title{
Discriminative and reinforcing effects of brotizolam in rhesus monkeys
}

\author{
Michael A. Nader ${ }^{1}$, Gail Winger ${ }^{3}$, James H. Woods ${ }^{3}$, and William L. Woolverton ${ }^{1,2}$ \\ ${ }^{1}$ Departments of Psychiatry and ${ }^{2}$ Pharmacological and Physiological Sciences, Pritzker School of Medicine, \\ The University of Chicago, Chicago, IL 60637, USA \\ ${ }^{3}$ Department of Pharmacology, University of Michigan Medical School, Ann Arbor, MI 48109, USA
}

Received May 18, 1990/Final version July 13, 1990

\begin{abstract}
The reinforcing and discriminative stimulus effects of brotizolam, a benzodiazepine-hypnotic, were evaluated in rhesus monkeys. In one experiment, separate groups of monkeys ( $N=3 /$ group) were trained to discriminate pentobarbital $(10 \mathrm{mg} / \mathrm{kg}, \mathrm{IG})$ or $d$-amphetamine $(0.56-1.0 \mathrm{mg} / \mathrm{kg}, \mathrm{IG})$ from saline, in a discrete-trials avoidance/escape paradigm. Pentobarbital $(5.6-10 \mathrm{mg} / \mathrm{kg})$, diazepam $(1.0-1.7 \mathrm{mg} / \mathrm{kg})$, and brotizolam $(0.3-1.7 \mathrm{mg} / \mathrm{kg}$ ) resulted in $100 \%$ drug-lever responding in all three pentobarbital-trained monkeys. In $d$-amphetamine-trained monkeys brotizolam administration resulted only in saline-lever responding. In another experiment, monkeys were surgically prepared with indwelling intravenous catheters and lever pressing resulted in an injection of $0.1 \mathrm{mg} / \mathrm{kg} /$ injection sodium methohexital under a fixed-ratio 10 (FR 10) schedule. Pentobarbital $(0.01-0.3 \mathrm{mg} / \mathrm{kg} /$ injection $)$ and diazepam $(0.003-0.10 \mathrm{mg} / \mathrm{kg} /$ injection) maintained responding above saline control levels when substituted for methohexital. Brotizolam $(0.001-0.01 \mathrm{mg} / \mathrm{kg} /$ injection) resulted in more injections received compared to saline, but fewer injections compared to pentobarbital or diazepam. Thus, results from the present experiment suggest that brotizolam would have pentobarbital-like subjective effects. However, the abuse liability of brotizolam may be lower than that for diazepam.
\end{abstract}

Key words: Drug discrimination - Self-administration Brotizolam - Pentobarbital - Rhesus monkeys

Brotizolam is a thienotriazolodiazepine hypnotic that has been reported to have clinical utility in the treatment of insomnia (Velasco et al. 1981; Mamelak et al. 1983, 1989; Roehrs et al. 1983; Rickels et al. 1986; Langley and Clissold 1988). Brotizolam has a half-life of $3-6 \mathrm{~h}$ (cf Rickels 1986), compared to diazepam with a half-life

Offprint requests to: M.A. Nader after oral administration of between approximately 20 and $96 \mathrm{~h}$ (Mandelli et al. 1978; Rall and Schleifer 1980). In a recent review, Langley and Clissold (1985) reported that brotizolam was at least as effective as other benzodiazepines in treating insomnia, and because of its intermediate elimination half-life, may have fewer side effects.

In animal studies, brotizolam has been shown to have behavioral effects similar to those of diazepam. For example, brotizolam increases rates of food-maintained responding that have been suppressed by punishment (Ueki et al. 1984), an effect that is characteristic of a number of antianxiety drugs (Sepinwall and Cook 1978; Barrett and Witkin 1990). Böke-Kuhn et al. (1986) reported that brotizolam increased punished responding of rats to a similar degree as diazepam and was equally effective as an anticonvulsant and antiaggressive agent. In addition, these investigators demonstrated that motor coordination was not impaired by brotizolam doses that were behaviorally active, suggesting that the differences between effective anxiolytic doses and doses with muscle relaxant effects may make brotizolam preferable to diazepam in the treatment of anxiety (Böke-Kuhn et al. 1986; Lehr et al. 1986).

Drug discrimination and drug self-administration procedures have been shown to be predictive of the abuse liability of drugs (see Johanson et al. 1987; Woolverton and Nader 1990). In the present study, the behavioral effects of brotizolam using these procedures were compared to those of two other sedative-hypnotics, diazepam and pentobarbital. Previous research has found that there is considerable cross-generalization among sedative/hypnotics of several chemical classes (Ator and Griffiths 1989). For example, when animals are trained to discriminate pentobarbital from saline, responding generalizes from the pentobarbital stimulus to other barbiturates and benzodiazepines. In the present study, one group of rhesus monkeys was trained to discriminate pentobarbital from saline, in a discrete-trials avoidance and escape paradigm, similar to the procedure described by Holtzman (1982). A second group was trained to 
discriminate amphetamine from saline. The discriminative stimulus effects of brotizolam were studied in both groups. To provide comparison data, diazepam was also tested in pentobarbital-trained monkeys.

A second series of experiments assessed whether brotizolam could function as a positive reinforcer. Most drugs that are abused by humans are self-administered by nonhuman animals (Griffiths et al. 1980). In general, injections of benzodiazepines can maintain responding of animals, although drugs of this class are less efficacious when compared to drugs such as cocaine and pentobarbital (cf Griffiths et al. 1985). The present study examined whether brotizolam could maintain responding when substituted for the ultra-short acting barbiturate sodium methohexital. In addition, the rate of responding maintained by brotizolam was compared with response rates maintained by diazepam and pentobarbital.

\section{Materials and methods}

\section{Experiment 1: Drug discrimination}

Subjects. Six adult rhesus monkeys (Macaca mulatta), two female $(\mathrm{M}-7976, \mathrm{M}-8515)$ and four male $(\mathrm{M}-8236, \mathrm{M}-8106, \mathrm{M}-7739$ and $\mathrm{M}-7737$ ), weighing between 7.0 and $13 \mathrm{~kg}$ served as subjects. All monkeys had received other test drugs prior to the start of the present study. Monkeys were individually housed in stainless steel cages with water available continuously. Supplemental feeding consisted of 100-150 g Purina Monkey Chow daily, 30 min after each session, and a chewable vitamin tablet 3 days/week.

Apparatus. During experimental sessions monkeys were seated in a restraining chair (Plas-Labs, Lansing, MI) and placed in a wooden cubicle (175 cm high $\times 85 \mathrm{~cm}$ wide $\times 65 \mathrm{~cm}$ deep) containing two response levers mounted $110 \mathrm{~cm}$ above the floor and a $40 \mathrm{~W}$ white houselight mounted on the ceiling. Above each lever were two sets of white jewel lights. The monkey's feet were placed into shoes, the bottoms of which were fitted with brass plates through which electric shocks could be delivered. Programming and recording of experimental events were accomplished by an Aim 65 microcomputer located in an adjacent room.

Procedure. All monkeys had previously been trained in a discretetrials shock avoidance/escape paradigm to discriminate either pentobarbital or $d$-amphetamine from saline ( $N=3$ /group). One hour after an intragastric infusion (via nasogastric tube) of the training drug (0.56-1.0 mg/kg d-amphetamine or $10 \mathrm{mg} / \mathrm{kg}$ pentobarbital) or saline, the houselight and lever lights were illuminated (trial) and a response on one lever (the correct lever) avoided electric shock and extinguished the lights. To prevent adventitious reinforcement of response chains, responding on the incorrect lever started a 2 -s change-over-delay during which correct responses had no programmed consequence. If a correct response was not made within $5 \mathrm{~s}$ following onset of the lights, electric shock $(250 \mathrm{~ms}$ duration, $7.0 \mathrm{~mA}$ intensity) was delivered every $2 \mathrm{~s}$ until a correct response was made (escape) or until two shocks had been delivered. Trials were separated by a 30 -s timeout. Sessions began with a 5 min timeout and ended after 30 trials or $20 \mathrm{~min}$, whichever came first. In addition, sessions were terminated early if two shocks occurred (i.e., no avoidance or escape responding) in two consecutive trials. The correct lever was determined by the infusion that was administered before the session. For three monkeys the right lever was correct after drug infusions and the left lever was correct after saline infusions. This condition was reversed for the other three monkeys.

Training sessions were conducted 5 days a week according to the following schedule: SDDSS, DSSDD, where S denotes saline trials and $D$ indicates sessions preceded by drug administration. Training of the drug-saline discrimination continued until a correct response was made on the first trial and on at least $90 \%$ of the total trials on at least seven out of eight consecutive sessions, at which point testing began. A test session was one in which different doses of the training drug or a drug other than the training drug was administered. Two different weekly sequences alternated drug, saline and test sessions so that the first test session each week was preceded by two training sessions, one with saline and one with drug pretreatment and the second test session of the week was preceded by either vehicle or drug pretreatment (i.e., SDTST, DSTDT, where $T$ denotes a test session). In the event that the criterion for stimulus control was not met during the training sessions, the training sequence continued. Test sessions were similar to training sessions except that a response on either lever prevented shock delivery.

Prior to testing brotizolam, a pentobarbital $(1.0-10 \mathrm{mg} / \mathrm{kg})$ or $d$-amphetamine $(0.03-1.0 \mathrm{mg} / \mathrm{kg})$ dose-response curve was determined, with doses administered in random order. Initial test doses of brotizolam were examined in an ascending order from $0.1 \mathrm{mg} / \mathrm{kg}$ to doses that either resulted in at least $90 \%$ drug-appropriate responding or increased response latency to the point that avoidance responding was disrupted. The three highest doses, in addition to the drug vehicle, were tested at least twice in each monkey. Pentobarbital-trained monkeys were also tested with diazepam $(0.3-1.7 \mathrm{mg} / \mathrm{kg})$.

\section{Experiment 2: Self-administration}

Subjects. Seven rhesus monkeys $(5.1-9.1 \mathrm{~kg})$, two of which were males (El and 1708), served as subjects. Monkeys were fed 100-150 g high protein Purina Monkey Chow twice daily, at least 30 min prior to initiation of each of two daily self-administration sessions. Silicone catheters were surgically implanted in a major vein (jugular, femoral or brachial) in each monkey using $10 \mathrm{mg} / \mathrm{kg} \mathrm{IM}$ ketamine and $15 \mathrm{mg} / \mathrm{kg}$ IV pentobarbital as anesthetics. The catheter passed subcutaneously from the site of implantation to the mid-scapular region, where it exited the monkey and continued, through a hollow restraining arm, to the outside rear of the cage. All but one subject $(600)$ had previous experience self-administering either cocaine or codeine. Two monkeys $(1708,833)$, in addition, had previously been exposed to schedules in which responding terminated drug infusions.

Apparatus. The restraint and catheter protection device has been described in detail by Deneau et al. (1969). Monkeys were individually housed in stainless steel cages, measuring $83.3 \times 76.2 \times 91.4 \mathrm{~cm}$ deep. Each monkey wore a tubular stainless steel harness that protected the exit site of the catheter and allowed relatively unrestricted movement within the chamber. Some monkeys wore a Teflon cloth jacket (Alice King Chatam Medical Arts, Los Angeles, CA) to provided further catheter protection. The harness was connected to a tubular, jointed arm that carried the catheter to the back of the cage where it joined tubing passing through a roller infusion pump (Watson and Marlow Co., Model MHRK 55; Falmouth, UK).

A $15.4 \mathrm{~cm}$ square stimulus panel was located on the side of each cage, approximately $10 \mathrm{~cm}$ from the front and $19 \mathrm{~cm}$ from the bottom of the cage. Across the top of the stimulus panel were three circles, $2.5 \mathrm{~cm}$ in diameter and $2.5 \mathrm{~cm}$ apart, covered with translucent plastic and capable of being transilluminated by $5 \mathrm{~W}$ colored bulbs. The two side lights could be illuminated red and the center light could be illuminated green. Below each of the two red stimulus lights was a response lever (Model 121-07; BRS-LVE, Beltsville, $\mathrm{MD}$ ), capable of being operated by $10-15 \mathrm{~g}$ force. Experimental control was provided by individual IBM PCjr computers located in an adjoining room. BASIC software was used to control experimental procedures.

Procedure. Monkeys were adapted to restraining arms for a week or more; then an intravenous catheter was implanted and they were 
given the opportunity to respond and receive drug. The beginning of a session was signalled by the illumination of a red light above one of two levers in each monkey's cage and initially each response produced a 5 -s injection of $0.1 \mathrm{mg} / \mathrm{kg}$ sodium methohexital. The number of responses required to deliver drug was gradually increased to 10 responses (fixed-ratio 10; FR 10), with each injection followed by a 10 -s timeout during which all stimulus lights were extinguished and responding had no programmed consequence. During an injection, the red lever light was extinguished and the green center light was illuminated. Experimental sessions were limited to 130 min or 200 infusions; however, no monkey ever received 200 injections of methohexital. Two sessions were scheduled each day, separated by at least $4 \mathrm{~h}$. During approximately one-half of the sessions saline was made available. When there was a clear difference in the number of injections of saline and methohexital, test compounds were substituted during single sessions, no more frequently than once every fourth session. Dose-response curves were determined for methohexital, pentobarbital, brotizolam and diazepam. Each dose was tested at least twice in three monkeys.

Drug administration. For the drug discrimination experiment, sodium pentobarbital (Sigma Chemical Co., St Louis, MO) and $d$ amphetamine (National Institute on Drug Abuse, Rockville, MD) were dissolved in saline, while brotizolam (obtained from the Committee on Problems of Drug Dependence) and diazepam (Hoffmann-La Roche, Nutley, NJ) were dissolved in an emulphor: $95 \%$ ethanol (1:1) vehicle. Approximately $1-11 \mathrm{ml}$ of drug was administered, followed by a $1 \mathrm{ml}$ saline flush. For self-administration studies, sodium methohexital (Eli Lilly, Indianapolis, IN) was dissolved in sterile water, diazepam was prepared in a solution containing commercial diluent (Hoffmann-La Roche) and sterile water, and brotizolam was dissolved in a Tween $80: 95 \%$ ethanol $(1: 1)$ vehicle and diluted with sterile water.

\section{Results}

\section{Drug discrimination}

In monkeys trained to discriminate pentobarbital from saline, pentobarbital $(3.0-10 \mathrm{mg} / \mathrm{kg})$ produced a dose- related increase in drug-appropriate responding (Fig. 1; left panel), with $100 \%$ drug-lever responding following administration of the training dose $(10 \mathrm{mg} / \mathrm{kg})$ in all monkeys. For two monkeys, doses lower than the training dose occasioned only saline-lever responding, while administration of $5.6 \mathrm{mg} / \mathrm{kg}$ resulted in $100 \%$ pentobarbital-lever responding in $\mathrm{M}-8106$ (Fig. 1). There was also a dose-related increase in response latency. Although response latency increased relative to saline controls, subjects rarely received shocks following pentobarbital.

Administration of diazepam $(0.3-1.7 \mathrm{mg} / \mathrm{kg})$ also resulted in a dose-related increase in pentobarbitalappropriate responding (Fig. 1; middle panel). For all subjects, diazepam substituted for pentobarbital at doses that increased response latency relative to saline controls. These increases in response latency were similar to the effects produced by the training dose of pentobarbital.

Brotizolam (0.03-3.0 mg/kg) occasioned $100 \%$ pentobarbital-lever responding in all three subjects tested (Fig. 1; right panel). In all pentobarbital-trained monkeys, initial administration of an intermediate dose of brotizolam resulted in $100 \%$ pentobarbital-appropriate responding. However, when these doses were retested, only partial substitution was observed. There was individual variability in the sensitivity to brotizolam, with $100 \%$ drug-lever responding occurring in each monkey between doses of 0.3 and $3.0 \mathrm{mg} / \mathrm{kg}$. Administration of the drug vehicle occasioned only saline-appropriate responding (data not shown). Brotizolam increased response latency in a dose-related manner. Doses of brotizolam that completely substituted for pentobarbital increased response latency relative to saline control. For M-7976 and M-8106, the highest dose of brotizolam disrupted avoidance responding; this dose was only tested once, since these monkeys were too sedated to be chaired following the second administration.
PENTOBARBITAL
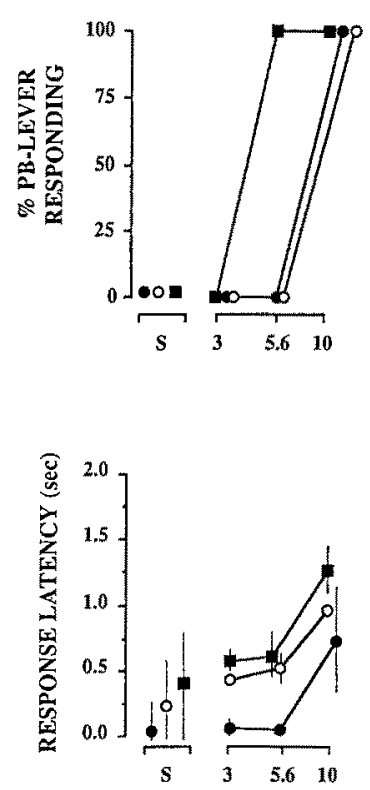

DIAZEPAM
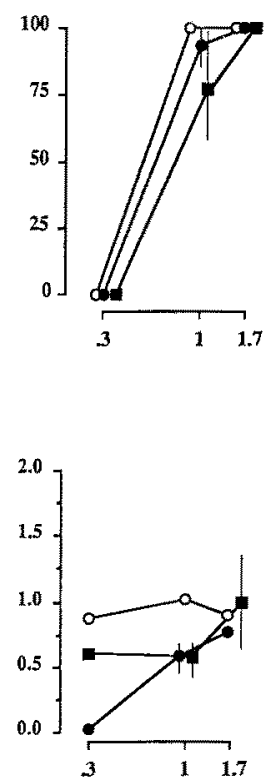

DOSE (mg/kg)
BROTIZOLAM
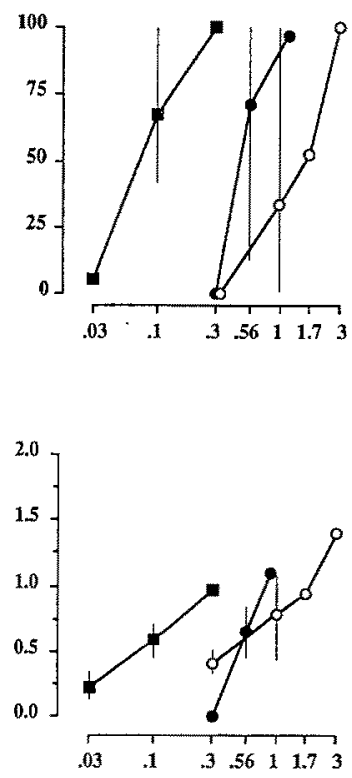

Fig. 1. Effects of pentobarbital, diazepam and brotizolam in rhesus monkeys trained to discriminate 10 $\mathrm{mg} / \mathrm{kg}$ pentobarbital from saline. The top panel represents the percentage of total responses during test sessions in which pentobarbital-lever responding occurred, while the lower panel depicts the average response latency per trial. Each point is the average of two to three determinations, except the highest dose of brotizolam in M-7976 and $\mathrm{M}-8106$, which was only tested once. The unconnected symbols at the far left represent the average of Thursday saline $(S)$ sessions. Each control point is the mean of at least ten sessions. Vertical lines represent the range of effects. - M-8236; O M-7976;

- $\mathrm{M}-8106$ 


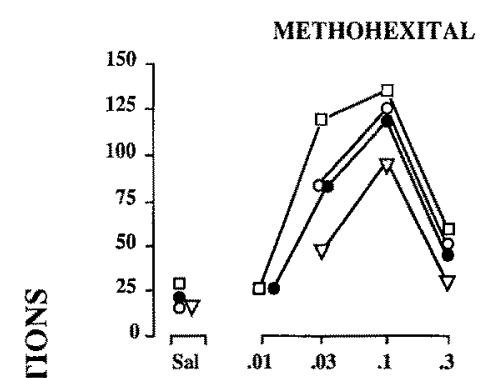

PENTOBARBITAL
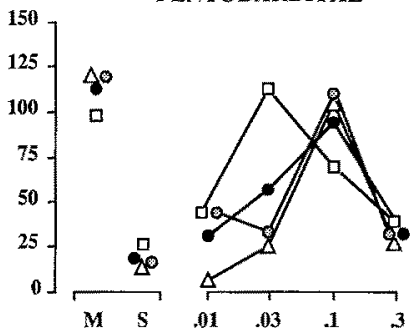
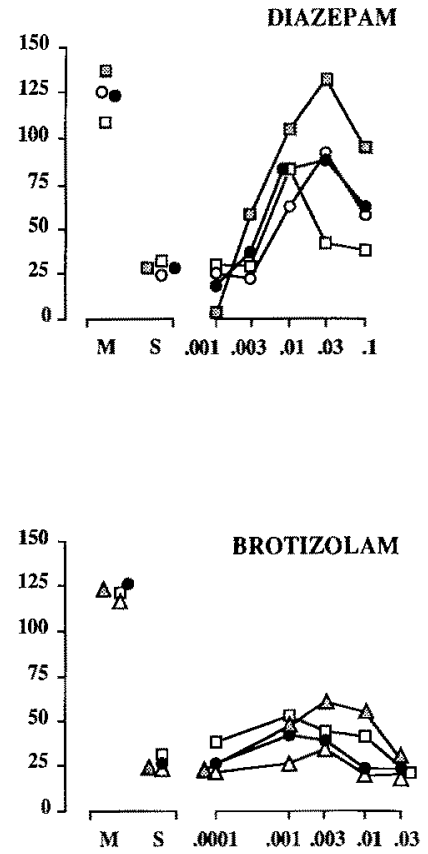

Fig. 2. Number of injections self-administered as a function of dose for methohexital, pentobarbital, diazepam and brotizolam. Each drug was tested in three monkeys and filled symbols represent the average.

Responding was maintained under a fixed-ratio 10 schedule and session length was $130 \mathrm{~min}$. Pentobarbital, diazepam and brotizolam were substituted for $0.1 \mathrm{mg} / \mathrm{kg} /$ injection methohexital. Each point is the mean of at least two determinations, except $0.03 \mathrm{mg} / \mathrm{kg} /$ injection methohexital for monkey 600 and $0.3 \mathrm{mg} / \mathrm{kg} /$ injection methohexital for subject 833 , which were determined once. Unconnected points at the left represent the number of injections received when saline or $0.1 \mathrm{mg} / \mathrm{kg} /$ injection methohexital was available for injection. $0833 ; \triangle 699$; $\square 583 \mathrm{C} ; \nabla 600 ; \quad 1708 ; \triangle \mathrm{E} 1$; 图 $\mathrm{Co}$; - average

DOSE (mg/kg/injection)

The training dose of $d$-amphetamine was $0.56 \mathrm{mg} / \mathrm{kg}$ for $\mathrm{M}-7737$ and $\mathrm{M}-7739$ and $1.0 \mathrm{mg} / \mathrm{kg}$ for $\mathrm{M}-8515$. During test sessions, the training dose and higher doses of amphetamine $(0.56-1.7 \mathrm{mg} / \mathrm{kg})$ resulted in $100 \%$ druglever responding (data not shown). These doses also increased response latency. In two monkeys (M-7737 and $M-8515$ ), a dose lower than the training dose completely substituted for amphetamine, whereas in all subjects the lowest dose tested $(0.1 \mathrm{mg} / \mathrm{kg})$ and saline resulted in $0 \%$ drug-lever responding.

Administration of brotizolam $(0.1-1.0 \mathrm{mg} / \mathrm{kg}$ ) resulted in only saline-lever responding in all amphetaminetrained monkeys (data not shown). Response latency increased in a dose-dependent manner in all subjects. For $\mathrm{M}-7739$, initial administration of brotizolam $0.3 \mathrm{mg} / \mathrm{kg}$ had no effect on response latency, while $1.0 \mathrm{mg} / \mathrm{kg}$ increased response latency and disrupted avoidance responding. When $0.3 \mathrm{mg} / \mathrm{kg}$ was retested several months after $1.0 \mathrm{mg} / \mathrm{kg}$, responding was completely eliminated. For the other two monkeys, avoidance responding was disrupted at doses of $0.1(\mathrm{M}-7737)$ and $0.56 \mathrm{mg} / \mathrm{kg}$ (M-8515).

\section{Self-administration}

Methohexital injections maintained responding in all subjects tested (Fig. 2). An inverted " $U$ " shaped function was observed in all three monkeys, with the highest number of injections (97-135 injections) occurring at a dose of $0.1 \mathrm{mg} / \mathrm{kg} /$ injection. When saline was made available following each FR 10, the number of injections received per session decreased to less than 30 for all three monkeys.
When pentobarbital was available a greater number of injections were received compared to saline in all three subjects tested (Fig. 2). At the most effective dose of pentobarbital $(0.03-0.10 \mathrm{mg} / \mathrm{kg} /$ injection), the number of injections received was similar to that observed when $0.10 \mathrm{mg} / \mathrm{kg}$ methohexital was available. Diazepam (0.01 - $0.10 \mathrm{mg} / \mathrm{kg} /$ injection) also consistently maintained responding when substituted for methohexital. For two monkeys, the most injections received occurred when $0.03 \mathrm{mg} / \mathrm{kg} /$ injection diazepam was available, while 0.01 $\mathrm{mg} / \mathrm{kg} /$ injection resulted in the largest number of diazepam injections in 583C (Fig. 2). Although diazepam was readily self-administered, the average number of injections received per session at optimal doses was lower than occurred at $0.1 \mathrm{mg} / \mathrm{kg} /$ injection methohexital.

For all subjects, when brotizolam $(0.0001-0.03 \mathrm{mg} /$ $\mathrm{kg}$ ) was available, more injections were received than when saline was available (Fig. 2). The number of injections received as a function of dose represented an inverted " $U$ " shaped curve, with the most injections delivered when $0.001 \mathrm{mg} / \mathrm{kg} /$ injection was available. Total number of injections decreased from an average of 126 when 0.1 $\mathrm{mg} / \mathrm{kg} /$ injection methohexital was available, to 42 injections when $0.001 \mathrm{mg} / \mathrm{kg} /$ injection brotizolam was available. Of the drugs studied in this experiment, brotizolam was the most potent. However, compared to the other drugs tested, brotizolam resulted in fewer number of injections received per session.

\section{Discussion}

The reinforcing and discriminative stimulus effects of the sedative/hypnotic benzodiazepine brotizolam were 
evaluated in rhesus monkeys and compared to diazepam and pentobarbital. In the drug discrimination study, brotizolam and diazepam completely substituted for pentobarbital in all monkeys tested. These findings are consistent with previous results showing that benzodiazepines can substitute for pentobarbital (Herling et al. 1980; Winger and Herling 1982; Ator and Griffiths 1983). Thus, results from the present study suggest that the subjective effects of brotizolam would be similar to those of other CNS depressants, such as pentobarbital and diazepam. On the other hand, when the discriminative stimulus effects of brotizolam were studied in monkeys trained to discriminate $d$-amphetamine from saline, no drug-lever responding was observed. Others have reported that administration of direct and indirect dopamine agonists, including dopamine reuptake blockers, can substitute for the amphetamine stimulus (Nielsen and Scheel-Krüger 1988). In that light, the present results in which brotizolam occasioned only saline-lever responding in amphetamine-trained monkeys are not surprising, since benzodiazepines have been shown to decrease dopamine turnover in brain (Corrodi et al. 1971; Ishiko et al. 1983).

When substituted for the maximum rate-maintaining dose of methohexital, one or more doses of pentobarbital maintained behavior to nearly the same extent as methohexital. Diazepam-maintained responding approximated that seen with pentobarbital and methohexital. In contrast, number of injections received when brotizolam was available was only slightly higher compared to saline. The finding that diazepam was a positive reinforcer in these monkeys was somewhat surprising, since diazepam has been found to maintain considerably less behavior than barbiturates in similar circumstances (Griffiths et al. 1985; Ator and Griffiths 1987). One variable that may have contributed to the clear reinforcing effects of diazepam in the present experimental paradigm was the fact that a sedative/hypnotic drug, methohexital, rather than a drug from another pharmacological class was used as the standard drug for selfadministration. Diazepam has been shown to maintain higher rates of responding when it was substituted on a pentobarbital baseline than when it was substituted on a cocaine baseline (Bergman and Johanson 1985). In addition, the fact that a low value fixed-ratio and a low value timeout were used to maintain the behavior may have contributed to diazepam's reinforcing effects. It has been shown by other investigators (Goldberg et al. 1971; C.E. Johanson, personal communication) that sedative/ hypnotics do not maintain behavior well when higher fixed-ratio values are used to maintain responding. Likewise, sedative/hypnotics are typically self-administered in a burst pattern (e.g., Winger et al. 1975), which is disrupted if long timeout values are programmed after each injection. If the burst pattern is allowed to develop by programming relatively short timeouts after each injection, self-administration of sedative/hypnotics may be more likely to occur.

Possible explanations for the reinforcing effects of diazepam do not explain the low number of injections received when brotizolam was available under these cir- cumstances. When two drugs have similar discriminative stimulus effects, but different reinforcing effects, it is sometimes the case, especially with opiates, that they differ in their pharmacokinetics (Bertalmio et al. 1990). Drugs with rapid onsets of action and short durations of action are more likely to maintain behavior, given that they have subjective effects in common with other reinforcing drugs, than are drugs with slow onsets and long durations of action. Brotizolam's onset of action following intravenous administration in monkeys has not been reported, but there is no a priori reason to think that it would be delayed relative to diazepam. Its duration of action is considerably shorter than that of diazepam, so that neither of these effects can easily account for the low rates of responding maintained by brotizolam. It is unlikely that general pharmacodynamic differences between triazolobenzodiazepines and more typical benzodiazepines can explain the differences observed here, since the triazolodiazepines triazolam and midazolam, when delivered intravenously and contingently to baboons, maintained higher rates of behavior than did diazepam (Griffiths et al. 1981, 1985). Thus, the resolution of this anomalous difference between the reinforcing effects of diazepam and brotizolam lies in further experiments on these two compounds.

Abuse liability of a compound is defined, at least in part, in terms of a drug's capacity to function as a positive reinforcer (cf Woods 1983; Woods et al. 1987). Based on the present results involving drug self-administration, it appears that the abuse liability of brotizolam is lower compared to diazepam. However, it should be emphasized that brotizolam would be predicted to have subjective effects in common with barbiturates, a class of drugs with established abuse liability. Abuse liability may also be assessed by the presence and severity of withdrawal signs following chronic administration. Stockhaus and Bechtel (1986) compared the physical dependence capacity of brotizolam with diazepam in rhesus monkeys. In that study both brotizolam and diazepam were administered by nasogastric tubes three times daily for 61 consecutive days. Tolerance did not develop to either drug's effects on motor coordination. After discontinuation of daily drug administration, withdrawal signs for brotizolam were evident on the first day, while the abstinence syndrome was highest on days $2-5$ following diazepam discontinuation. Most withdrawal symptoms following chronic brotizolam had faded by day 2 . The doses used to induce physical dependence in this study were 500- and 96-times the therapeutic human dose for brotizolam and diazepam, respectively. Stockhaus and Bechtel's (1986) results suggest that withdrawal from daily brotizolam treatment would produce less behavioral disruption than withdrawal from diazepam. These data, taken together with the results from the present self-administration study, suggest that the abuse liability of brotizolam may be lower than that for diazepam.

Acknowledgements. This research was supported by the Committee on Problems of Drug Dependence and NIDA grant DA-05951. We are grateful to Robert L. Balster, Mark S. Kleven and James P. Zacny for comments on an earlier version of this manuscript and 
Laura Galoski, Laurie Heller and Kirsten Roberts for excellent technical assistance.

\section{References}

Ator NA, Griffiths RR (1983) Lorazepam and pentobarbital drug discrimination in baboons: cross-drug generalization and interaction with Ro 15-1788. J Pharmacol Exp Ther 226: 776-782

Ator NA, Griffiths RR (1987) Self-administration of barbiturates and benzodiazepines: a review. Pharmacol Biochem Behav 27:391-398

Ator NA, Griffiths RR (1989) Asymmetrical cross-generalization in drug discrimination with lorazepam and pentobarbital training conditions. Drug Dev Res 16:355-364

Barrett JE, Witkin JM (1990) Buspirone in animal models of anxiety. In Tunnicliff G, Eison AS, Taylor DP (eds), Buspirone: mechanisms and chinical aspects. Academic Press, New York (in press)

Bergman $J$, Johanson CE (1985) The reinforcing properties of diazepam under several conditions in the rhesus monkey. Psychopharmacology 86:108-113

Bertalmio AJ, Medzihradsky F, Winger G, Woods JH (1990) Differential influence of $n$-dealkylation on the stimulus properties of some opioid agonists. J Pharmacol Exp Ther (in press)

Böke-Kuhn K, Danneberg P, Kuhn FJ, Lehr E (1986) Antiemotional and anticonvulsant activity of brotizolam and its effects on motor performance in animals. Arzneimittelforschung $36: 528-531$

Corrodi H, Fuxe K, Lidbrink P, Olson L (1971) Minor tranquilizers, stress and central catecholamine neurons. Brain Res $29: 1-16$

Deneau G, Yanagita T, Seevers MH (1969) Self-administration of psychoactive substances by the monkey. Psychopharmacology $16: 30-48$

Goldberg SR, Hoffmeister RF, Schlichting UU, Wuttke W (1971) A comparison of pentobarbital and cocaine self-administration in rhesus monkeys: effects of dose and fixed-ratio parameter. J Pharmacol Exp Ther 179:277-283

Griffiths RR, Bigelow GE, Henningfield JH (1980) Similarities in animal and human drug-taking behavior. In: Mello NK (ed) Advances in substance abuse, vol. 1. JAI Press, Greenwich, Connecticut pp: $1-90$

Griffiths RR, Lukas SE, Bradford LD, Brady JV, Snell J (1981) Self-injection of barbiturates and benzodiazepines in baboons. Psychopharmacology 75:101-109

Griffiths RR, Roache JD, Ator NA, Lamb RJ, Lukas SE (1985) Similarities in reinforcing and discriminative stimulus effects of diazepam, triazolam, and pentobarbital in animals and humans. In: Seiden LS, Balster RL (eds) Behavioral pharmacology: the current status. Liss, New York, pp $419-432$

Herling S, Valentino RJ, Winger GD (1980) Discriminative stimulus effects of pentobarbital in pigeons. Psychopharmacology $71: 21-28$

Holtzman SG (1982) Phencyclidine-like discriminative stimulus properties of opioids in the squirrel monkey. Psychopharmacology $77: 295-300$

Ishiko J, Inagaki C, Takaori S (1983) Inhibitory effects of brotizolam, a new thienodiazepine, on limbic forebrain and neostriatal dopaminergic systems in vivo and in vitro. Neuropharmacology $22: 221-226$
Johanson CE, Woolverton WL, Schuster CR (1987) Evaluating laboratory models of drug dependence. In: Meltzer HY (ed) Psychopharmacology: the third generation of progress. Raven Press, New York, pp 1617-1625

Langley MS, Clissold SP (1988) Brotizolam. A review of its pharmacodynamic and pharmacokinetic properties, and therapeutic efficacy as an hypnotic. Drugs $35: 104-122$

Lehr E, Böke-Kuhn D, Danneberg P (1986) Therapeutic safety studies of brotizolam in animals. Arzneimittelforschung 36:532-533

Mamelak M, Csima A, Price V (1983) Effects of brotizolam on sleep of chronic insomniacs. Br J Clin Pharmacol 16:377S-382S

Mamelak M, Csima A, Buck L, Price V (1989) A comparative study on the effects of brotizolam and flurazepam on sleep and performance in the elderly. J Clin Psychopharmacol 9:260-267

Mandelli M, Tognoni G, Garattini S (1978) Clinical pharmacokinetics of diazepam. Clin Pharmacokinet 3:72-91

Nielsen EB, Scheel-Krüger J (1988) Central nervous system stimulants: Neuropharmacological mechanisms. In: Colpaert FC, Balster RL (eds) Transduction mechanisms of drug stimuli. Springer Heidelberg New York, Berlin, pp 57-72

Rall TW, Schleifer LS (1980) Drugs effective in the therapy of the epilepsies. In: Gilman $\mathrm{AG}_{3}$ Goodman LS, Gilman A (eds) The pharmacological basis of therapeutics, 6th edn. Macmillan, New York, pp 448-474

Rickels K (1986) The clinical use of hypnotics: indications for use and the need for a variety of hypnotics. Acta Psychiat Scand [Suppl. 332] 74:132 -141

Rickels K, Morris R, Mauriello R, Rosenfeld H, Chung E (1986) Brotizolam, a triazolo, thieno-diazepine in insomnia. Clin Pharmacol Ther 40:293-299

Roehrs T, Zonick F, Koshoret G, Wittig R, Roth T (1983) Effects of acute administration of brotizolam in subjects with disturbed sleep. Br J Clin Pharmacol 16:371S-376S

Sepinwall J, Cook L (1978) Behavioral pharmacology of antianxiety drugs. In: Iversen LL, Iversen SD, Snyder SH (ed) Handbook of psychopharmacology, vol. 13. Plenum Press, New York, pp 345-393

Stockhaus K, Bechtel WD (1986) Physical dependence capacity of brotizolam in rhesus monkeys. Arzneimittelforschung $36: 597-600$

Ueki S, Watanabe S, Yamamoto T, Shibata S, Shibata K (1984) Behavioral effects of brotizolam, a new thienotriazolodiazepine derivative. Jpn J Pharmacol 35:287-299

Velasco M, Velasco F, Cepeda C, Romo R, Perez-Toledo M (1981) Effect of a new thienodiazepine (WE941) on sleep patterns of normal and insomniac subjects. Neuropharmacology $20: 461-468$

Winger G, Herling S (1982) Discriminative stimulus effects of pentobarbital in rhesus monkeys: tests of stimulus generalization and duration of action. Psychopharmacology 76:172-176

Winger $\mathrm{G}$, Stitzer ML, Woods JH (1975) Barbiturate-reinforced responding in rhesus monkeys: comparison of drugs with different durations of action. J Pharmacol Exp Ther 195: 505-514

Woods JH (1983) Experimental abuse liability assessment of benzodiazepines. J Psychoactive Drugs 15:61-65

Woods JH, Katz JL, Winger G (1987) Abuse liability of benzodiazepines. Pharmacol Rev 39:251-413

Woolverton WL, Nader MA (1990) Methods for studying the reinforcing effects of drugs. In: Adler MW (ed) Testing and evaluation of drugs of abuse. Liss, New York, pp 165-192 